\title{
Microrganismos heterotróficos mesófilos e bactérias do grupo do Bacillus cereus em leite integral submetido a ultra alta temperatura
}

\author{
[Mesophilic heterotrophic microorganisms and spore forming bacteria from Bacillus cereus group \\ in ultra high temperature milk]
}

\author{
A.M.C. Vidal-Martins, O.D. Rossi Jr. *, N.C. Rezende-Lago \\ Faculdade de Ciências Agrárias e Veterinárias - UNESP \\ Via de Acesso Prof. Paulo Donato Castellane, km5 \\ 14884-900 - Jaboticabal, SP
}

\begin{abstract}
RESUMO
Cento e dez amostras de 11 diferentes marcas de leite ultra alta temperatura (UAT), comercializadas em São José do Rio Preto - SP, foram submetidas à contagem de microrganismos heterotróficos mesófilos viáveis e à pesquisa de bactérias do grupo do Bacillus cereus. A população de microrganismos mesófilos variou de $<1,0 \times 10^{2} \mathrm{UFC} / \mathrm{ml}$ a $\geq 1,0 \times 10^{6} \mathrm{UFC} / \mathrm{ml}$. Bactérias do grupo do Bacillus cereus foram verificadas em $13(11,8 \%)$ amostras. Os resultados evidenciaram elevada população de microrganismos indicadores mesófilos.
\end{abstract}

Palavras-chave: Bacillus cereus, leite UAT, microrganismos mesófilos

\begin{abstract}
One hundred and ten ultra high temperature (UHT) milk samples, from 11 different brands retailed in São José do Rio Preto - SP were analysed for mesophilic heterotrophic microorganisms counting, as well as for the presence of Bacillus cereus. Mesophilic heterotrophic microorganisms ranged from $<1.0 \times 10^{2}$ CFU/ml to $\geq 1.0 \times 10^{6} \mathrm{CFU} / \mathrm{ml}$. Bacillus cereus was detected in 13 (11.8\%) samples. The results demonstrated high countings of mesophilic microorganisms.
\end{abstract}

Keywords: Bacillus cereus, UHT milk, mesophilic microorganisms

\section{INTRODUÇÃO}

O leite é considerado alimento rico em componentes nutritivos, constituindo-se em ótimo meio de cultura para vários microrganismos. Quando obtido ou processado em más condições higiênico-sanitárias, pode tornar-se importante veículo de transmissão de microrganismos patogênicos ao homem (Hoffmann et al.,1999; Ponsano et al., 1999; Franco et al., 2000).
Segundo Panetta (1999), os processos de beneficiamento garantem a qualidade do leite. $\mathrm{O}$ tratamento térmico é relevante na evolução da tecnologia alimentar (Bastos, 1999). Ele é eficiente se for respeitado o binômio tempo $x$ temperatura, para que sejam eliminados os microrganismos e preservadas as características sensoriais e o valor nutricional do produto. No mercado são encontrados leites tratados pelo calor, como é o caso do leite pasteurizado, e leite submetido a ultra alta temperatura (UAT) ou longa vida (Prata, 1998).

Recebido para publicação em 20 de fevereiro de 2002

Recebido para publicação, após modificações, em 29 de março de 2003

*Autor para correspondência (corresponding author)

E-mail: rossijr@fcav.unesp.br 
Os termos UAT e longa vida têm sido usados para designar produtos lácteos submetidos ao tratamento em alta temperatura e embalados assepticamente. Esses produtos têm longa vida na prateleira, sem refrigeração (Dunkley e Stevenson, 1987).

No Brasil, o leite UAT geralmente é obtido e transportado sob condições precárias, constituindo um dos principais problemas de garantia da qualidade do produto (Gillis et al., 1985; Prata, 1998; Bastos, 1999).

A legislação brasileira até o início de 2001 (Brasil, 1996; Brasil, 1997) estabelecia que o leite UAT não deveria ter microrganismos capazes de proliferarem sob condições normais de armazenamento e distribuição. Pelas normas, após incubação da embalagem fechada a $35-37^{\circ} \mathrm{C}$ durante sete dias, não poderia conter mais que 100 microrganismos mesófilos $/ \mathrm{ml}$. Atualmente (Brasil, 2001), após sete dias de incubação a 35$37^{\circ} \mathrm{C}$ em embalagem fechada, não deve apresentar microrganismos patogênicos e causadores de alterações físicas, químicas e organolépticas.

Apesar de o tratamento UAT eliminar totalmente as formas vegetativas de microrganismos presentes no leite, formas esporuladas, altamente resistentes ao calor, (highly heat resistant spores - HHRS), poderão estar presentes no produto, decorrentes das condições precárias de obtenção da matéria-prima (Foschino et al., 1990; Schocken-Iturrino et al., 1996). As principais bactérias esporuladas, as mais resistentes ao calor e de importância na microbiologia alimentar, pertencem aos gêneros Bacillus e Clostridium (Rangasamy et al., 1993; Cosentino et al., 1997).

Entre as espécies do gênero Bacillus, uma das mais importantes na indústria de alimentos é o $B$. cereus, tendo em vista sua capacidade de produzir toxinas, responsáveis por toxinfecções alimentares, enzimas extracelulares, que determinam o potencial de deterioração, e esporos, que podem resistir ao tratamento UAT (Robinson e Phill, 1987).

Rangasamy et al. (1993), ao estudarem 91 amostras de leite e produtos lácteos coletados em Vitória, Austrália, encontraram B. cereus em $26,4 \%$ das amostras analisadas, exceto em amostras de leite UAT. Schocken-Iturrino et al. (1996), ao analisarem 32 caixas de leite longa vida de quatro marcas diferentes na região de Ribeirão Preto, SP, verificaram a presença de bactérias do gênero Bacillus em 19 (59,3\%) delas.

Rezende et al. (2000b) analisaram 120 amostras de leite UAT de quatro marcas diferentes e encontraram espécies do grupo do Bacillus cereus em 34,1\% delas. Bahout (2000), ao estudar 60 amostras de leite UAT no Egito, encontrou Bacillus sp. em 18,3\% e Bacillus cereus em 29,2\% delas. O autor concluiu que, para a produção de leite UAT de boa qualidade, seriam necessários o controle microbiológico do leite cru, a adequada e eficiente limpeza dos equipamentos e o apropriado processo de tratamento térmico.

O estudo teve por objetivo avaliar as características microbiológicas do leite UAT integral comercializado em São José do Rio Preto, SP.

\section{MATERIAL E MÉTODOS}

Foram analisadas 110 amostras de leite UAT integral, de 11 diferentes marcas comerciais nacionais, sendo 10 amostras de cada marca, divididas em dois lotes de cinco, com o objetivo de avaliar maior número de partidas de leite de cada marca. As amostras foram adquiridas aleatoriamente no comércio (supermercados) de São José do Rio Preto, SP, entre junho e dezembro de 2000.

No laboratório, as embalagens fechadas foram incubadas a $35-37^{\circ} \mathrm{C}$ durante sete dias, segundo a legislação vigente (Brasil, 1996; Brasil, 2001).

Para a contagem padrão em placas de microrganismos heterotróficos aeróbios ou facultativos, mesófilos viáveis (Asperger, 1991), foram preparadas diluições decimais usando água peptonada a $0,1 \%$, as quais foram depositadas no fundo de placas de Petri (técnica de pour plate) e, após adição do ágar, homogeneização e solidificação, foram incubadas a $30^{\circ} \mathrm{C}$ por 72 horas. As contagens foram realizadas em contador de colônias, nas placas cujas diluições apresentavam entre $10 \mathrm{e}$ 300 unidades formadoras de colônias (UFC). 
Para a pesquisa de células vegetativas e esporos de bactérias do grupo do Bacillus cereus, foi realizado o enriquecimento seletivo em caldo de soja triptona (TSB), adicionado de polimixina B (Stadhouders, 1992b), seguido de incubação a $30^{\circ} \mathrm{C}$ por $24-30$ horas e plaqueamento seletivo em ágar manitol-gema de ovo-polimixina $\mathrm{B}$ (MYP). Após incubação a $30^{\circ} \mathrm{C}$ por $18-40$ horas, foram tomadas de três a cinco UFC, sugestivas das espécies do grupo do Bacillus cereus (Mossel et al., 1967), repicadas em tubos contendo ágar soja triptona (TSA) inclinado. Os esfregaços foram preparados para coloração de Gram e de Wirtz-Conklin (Bier, 1975). Constatada a presença de bastonetes Gram positivos com esporo centro-terminal, foram realizadas provas para a caracterização bioquímica e confirmação do grupo do Bacillus cereus (American..., 1992).

\section{RESULTADOS E DISCUSSÃO}

$\mathrm{Na}$ Tab. 1 são apresentados o número de amostras de leite UAT analisadas segundo o lote, a marca estudada e o número de amostras positivas e negativas para a presença de bactérias do grupo do Bacillus cereus.

O número de amostras positivas para Bacillus cereus foi pequeno e o de marcas com amostras positivas foi alto, $8 \mathrm{em} \mathrm{11,} \mathrm{o} \mathrm{que} \mathrm{torna} \mathrm{o}$ problema preocupante.

Rezende et al. (2000b), ao analisarem 120 amostras de quatro diferentes marcas de leite UAT da região de Ribeirão Preto, SP, encontraram bactérias do grupo do Bacillus cereus em $34,1 \%$ das amostras estudadas, número superior ao verificado no presente estudo. Os autores atribuíram a alta positividade de amostras contaminadas às más condições higiênico-sanitárias adotadas no processo de obtenção do leite cru destinado à produção de leite UAT e indicaram a necessidade de melhorias para minimizar as contaminações encontradas. Schocken-Iturrino et al. (1996) analisaram 32 amostras de leite longa vida de quatro diferentes marcas na mesma região e encontraram $19(59,3 \%)$ amostras contaminadas com Bacillus sp. Ao concluírem que o tratamento térmico foi insuficiente para a destruição dos esporos, recomendaram que se estabelecessem padrões nacionais específicos para o leite UAT, quanto às bactérias dos gêneros Bacillus e Clostridium.

Tabela 1. Número e porcentagem de amostras de leite UAT comercial positivas para Bacillus cereus adquiridas na cidade de São José do Rio Preto, SP, segundo a marca e o lote analisado

\begin{tabular}{lccc}
\hline Marca $^{1}$ & Lote & N. $^{\circ}$ & $\%$ \\
\hline A & 1 & - & - \\
& 2 & 1 & 20 \\
B & 1 & - & - \\
& 2 & 1 & 20 \\
C & 1 & 1 & 20 \\
& 2 & 1 & 20 \\
D & 1 & - & - \\
& 2 & 4 & 80 \\
E & 1 & - & - \\
& 2 & 2 & 40 \\
F & 1 & - & - \\
& 2 & - & - \\
G & 1 & - & - \\
& 2 & - & - \\
H & 1 & - & - \\
& 2 & 1 & 20 \\
I & 1 & 1 & 20 \\
& 2 & - & - \\
J & 1 & - & - \\
& 2 & - & - \\
L & 1 & - & - \\
Total & 2 & 1 & 20 \\
\hline
\end{tabular}

${ }^{1}$ Marcas divididas em dois lotes de cinco amostras cada.

De acordo com Bergère e Cerf (1992), o tratamento UAT é suficiente para reduzir a população de esporos de Bacillus cereus a um valor que não causa risco à saúde pública. A presença de Bacillus cereus em leite UAT pode ser atribuída, segundo os autores, à alta população de esporos no leite cru, à utilização de tratamento térmico insuficiente ou à contaminação pós-tratamento térmico. Bahout (2000), ao analisar 60 amostras de leite UAT no Egito, verificou a presença de Bacillus cereus em $29,2 \%$ das $11(18,3 \%)$ amostras positivas para Bacillus sp. e concluiu que a sua presença poderia ser atribuída aos fatores citados. Foschino et al. (1990) encontraram baixa concentração de Bacillus cereus $(3,1 \%) \mathrm{em}$ amostras de leite UAT positivas para microrganismos do gênero Bacillus.

Zacarchenco et al. (2000) analisaram 100 amostras de leite UAT processados pelo método de injeção direta e indireta de vapor e verificaram que $22 \%$ das amostras processadas 
pelo sistema direto e $71,4 \%$ pelo indireto apresentavam o Bacillus sp. na forma de esporos de alta resistência térmica (HHRS). Os autores salientaram que os HHRS parecem resistir às condições de tempo e temperatura empregadas, principalmente no sistema de injeção indireta de vapor, trazendo preocupação pela possibilidade de prejuízos com a condenação do produto.

Os resultados diferem daqueles descritos por Cosentino et al. (1997), na Itália. Esses autores encontraram Bacillus sp. em $30,0 \%$ das 60 amostras de leite UAT analisadas, mas nenhum deles Bacillus cereus.

Os resultados da Tab. 2 mostram a distribuição das amostras analisadas, segundo a população de microrganismos heterotróficos aeróbios ou facultativos mesófilos viáveis.

Tabela 2. Distribuição das amostras de leite UAT de 11 marcas comerciais adquiridas na cidade de São José do Rio Preto, SP, segundo a população de microrganismos heterotróficos mesófilos viáveis

\begin{tabular}{|c|c|c|c|c|c|c|c|c|c|c|c|c|c|c|c|c|c|c|c|c|c|c|c|c|}
\hline \multirow{2}{*}{$\begin{array}{l}\text { População } \\
\text { (UFC/ml) }\end{array}$} & \multicolumn{2}{|c|}{ A } & \multicolumn{2}{|c|}{ B } & \multicolumn{2}{|c|}{$\mathrm{C}$} & \multicolumn{2}{|c|}{$\mathrm{D}$} & \multicolumn{2}{|c|}{$\mathrm{E}$} & \multicolumn{2}{|c|}{$\mathrm{F}$} & \multicolumn{2}{|c|}{$\mathrm{G}$} & \multicolumn{2}{|c|}{$\mathrm{H}$} & \multicolumn{2}{|c|}{ I } & \multicolumn{2}{|c|}{$\mathrm{J}$} & \multicolumn{2}{|c|}{$\mathrm{L}$} & \multirow{2}{*}{$\mathrm{N}$} & \multirow{2}{*}{$\%$} \\
\hline & 1 & 2 & 1 & 2 & 1 & 2 & 1 & 2 & 1 & 2 & 1 & 2 & 1 & 2 & 1 & 2 & 1 & 2 & 1 & 2 & 1 & 2 & & \\
\hline$<1,0 \times 10^{2}$ & 5 & 2 & 5 & 4 & 5 & & 5 & 3 & 5 & 4 & 5 & & 5 & 5 & 5 & 4 & & 4 & 5 & 5 & 5 & 4 & 85 & 77,3 \\
\hline $1,0 \times 10^{5} \mid-5,0 \times 10^{5}$ & & 2 & & & & & & 3 & & 1 & & & & & & & & & & & & & 4 & $3,6^{*}$ \\
\hline $5,0 \times 10^{5} \mid-1,0 \times 10^{6}$ & & 1 & & & & & & 1 & & & & & & & & & & & & & & & 2 & $1,3^{*}$ \\
\hline$\geq 1,0 \times 10^{6}$ & & & & 1 & & 5 & & & & & & 5 & & & & 1 & 5 & 1 & & & & 1 & 19 & $17,3^{*}$ \\
\hline
\end{tabular}

Oitenta e cinco amostras apresentaram-se dentro do padrão regulamentar (inferior a 100 microrganismos mesófilos $/ \mathrm{ml}$ ) estabelecido (Brasil, 1996), e 25 (22,7\%) amostras de nove $(81,8 \%)$ marcas apresentaram população de microrganismos fora do padrão. Essas amostras devem ser motivo de preocupação das autoridades sanitárias da área. Apenas duas marcas não apresentaram amostra fora do padrão nos dois lotes, e as demais apresentaram-se dentro do padrão em apenas um dos lotes.

Os microrganismos mesófilos fornecem informações sobre as características higiênicosanitárias do processamento e armazenamento do produto. A diferença observada entre as marcas pode ser atribuída a vários fatores como: qualidade do leite cru (matéria-prima) e da água utilizada na higienização dos equipamentos, não treinamento da mão-de-obra empregada, processamento inadequado do leite e contaminação pós-tratamento térmico (Foschino et al., 1990; Bahout, 2000).

Gillis et al. (1985) verificaram que as amostras de leite cru com elevada população microbiana (contagem padrão em placa e microrganismos psicrotróficos) resultaram em menor vida útil do leite UAT, pelo desenvolvimento de "off flavors". Os resultados diferem dos encontrados por Pereira et al. (2000). Esses autores não encontraram amostras fora dos padrões estabelecidos pela legislação brasileira.

Rezende et al. (2000a) verificaram que das 120 amostras de leite UAT analisadas, 36 (30,0\%) não atenderam ao padrão estabelecido pela legislação brasileira para microrganismos heterotróficos aeróbios ou facultativos mesófilos viáveis.

Conclui-se que a elevada população de microrganismos indicadores mesófilos sugere a necessidade de melhoras higiênico-sanitárias em todo o fluxograma de processamento do leite UAT, e que e a presença de bactérias do grupo do Bacillus cereus pode causar prejuízos para as indústrias e colocar em risco a saúde do consumidor.

\section{REFERÊNCIAS BIBLIOGRÁFICAS}

AMERICAN Public Health Association (APHA). Committee on microbiological methods for foods. Compendium of methods for the microbiological examination of foods. Washington: American Public Health Association, 1992. 1219p.

ASPERGER, H. (Coord.). Milk and milk products enumeration of microorganisms colony count technique at $30^{\circ}$ C. Bull. Int. Dairy Fed., n.100B, p.1-3, 1991. 
BAHOUT, A.A. Prevalence of Bacillus species in UHT milk. Assoc. Vet. Med. J., v.42, p.47-53, 2000.

BASTOS, M.S.R. Leite longa vida UHT: Aspectos do processamento e identificação dos pontos críticos de controle. Hig. Aliment., v.13, p.32-36, 1999.

BERGÈRE, J.L.; CERF, O.C. Heat resistance of Bacillus cereus spores. Bull. Int. Dairy Fed., n.275, p.23-25, 1992.

BIER, O. Bacteriologia e imunologia: em suas aplicações à medicina e à higiene. 16.ed. São Paulo: Melhoramentos, 1975. p.842-843.

BRASIL. Portaria n.146, 7 mar. 1996. Regulamentos técnicos de identidade e qualidade de produtos lácteos. Diário Oficial da União, Brasilia, DF, n.48, p.39773986, Seção1.

BRASIL. Portaria n.451, 19 set. 1997. Regulamentos técnicos - Princípios gerais para o estabelecimento de critérios e padrões microbiológicos para alimentos. Diário Oficial da União, Brasília, DF, n.182, p.21005210112, Seção1.

BRASIL Resolução - RDC n.12, 2 jan. 2001. Revoga Portaria n.451, 19 set. 1997. Diário Oficial da União, Brasilia, DF, art. $4^{\circ}$, p.1-48.

COSENTINO, S.; MULARGIA, A.F.; PISANO, B. et al. Incidence and biochemical characteristics of Bacillus flora in Sardinian dairy products. Int. J. Food Microbiol., v.38, p.235-238, 1997.

DUNKLEY, W.L.; STEVENSON, K.E. Ultra hight temperature processing and aseptic packaging of dairy products. J. Dairy Sci., v.70, p.2192-2202, 1987.

FOSCHINO, R.; GALLI, A.; OTTOGALLI, G. Research on the microflora of UHT milk. Ann. Microbiol., v.40, p.47-59. 1990.

FRANCO, R.M.; CAVALCANTI, R.M.S.; WOOD, P.C.B. et al. Avaliação da qualidade higiênicosanitária de leite e derivados. Hig. Aliment., v.14, p.70-77, 2000.

GILLIS, W.T.; CARTLEDGE, M.F.; RODRIGUES, I.R. et al. Effect of raw milk quality on ultra high temperature processed milk. J. Dairy Sci., v.68, p.2875-2879, 1985.

HOFFMANN, F.L.; GARCIA-CRUZ, C.H.; VINTURIM, T.M. et al. Microbiologia do leite pasteurizado tipo $\mathrm{C}$, comercializado na região de São José do Rio Preto-SP. Hig. Aliment., v.13, p.51-54, 1999.
MOSSEL, D.A.A.; KOOPMAN, M.J.; JONGERIUS, E. Enumeration of Bacillus cereus in foods. Appl. Microbiol., v.15, p.650-653, 1967.

PANETTA, J.C. Denúncias sobre a qualidade do leite são procedentes? Hig. Aliment., v.13, p.3-4, 1999.

PEREIRA, A.I.B.; MARTINS, S.C.S.; ALBUQUERQUE, L.M.B. Bactérias extremofílicas termófilas, em leite comercial estéril. Hig. Aliment., v.14, p.40-44, 2000.

PONSANO, E.H.G.; PINTO, M.F.; FERREIRA de LARA, J.A. et al. Variação sazonal e correlação entre propriedades do leite utilizadas na avaliação de qualidade. Hig. Aliment., v.13, p. 35-40, 1999.

PRATA, L.F. Leite UHT: solução ou problema? Uma análise da situação. Hig. Aliment., v.12, p.10-15, 1998.

RANGASAMY, P.N.; IYER, M.; ROGINSKI, H. Isolation and characterisation of Bacillus cereus in milk and dairy products manufactured in Victoria. Aust. J. Dairy Technol., v.48, p.93-95, 1993.

REZENDE, N.C.M.; ROSSI Jr., O.D.; NADER FILHO, A. et al. Ocorrência de microrganismos indicadores em leite UHT ("ultra-high-temperature") integral. Rev. Bras. Ciên. Vet., v.7, p.58-60, 2000a.

REZENDE, N.C.M.; ROSSI Jr., O.D.; AMARAL, L.A. Ocorrência de bactérias do grupo do Bacillus cereus em leite UHT integral (ultra-high-temperature). Rev. Bras. Ciên. Vet., v.7, p.162-166, 2000 b.

ROBINSON, R.K.; PHILL, M.A.D. Microbiologia lactológica. Zaragoza: Acribia, 1987. p.18-32.

SCHOCKEN-ITURRINO, R.P.; NADER FILHO, A.; DIMENSTEIN, A.R. Ocorrência de bactérias esporuladas do gênero Bacillus e Clostridium em amostras de leite longa vida. Hig. Aliment., v.10, p.2527, 1996.

STADHOUDERS, J. Taxonomy of Bacillus cereus. Bull. Int. Dairy Fed., n.275, p.4-8, 1992a.

STADHOUDERS, J. The enumeration of spores and vegetative cells of Bacillus cereus. Bull. Int. Dairy Fed., n.275, p.15-18, 1992b.

VARNAM, A.H.; EVANS, M.G. Bacillus. In: Foodborne Pathogens. London: Mosby Year Book, 1991. p.267-288.

ZACARCHENCO, P.B.; LEITÃO, M.F.F.; DESTRO, M.T. et al. Ocorrência de Bacillus sporothermodurans em leite UAT/UHT brasileiro e a influência do tratamento térmico. Ciên. Tecnol. Aliment., v.20, p.363-368, 2000. 